\title{
A Construção da Cooperação Jurisdicional nos Pressupostos Teóricos da Obra de Pasquale Stanislao Mancini (1851-1872)
}

\author{
Arno Dal Ri Júnior ${ }^{1}$ \\ Ademar Pozzatti Júnior²
}

Resumo: O presente artigo traça uma evolução histórica do Direito Internacional Privado (DIPr), sobretudo do ideal de cooperação jurisdicional, entre o Medievo e a Modernidade. Analisa-se a obra de Pasquale Stanislao Mancini e a sua noção de comunidade internacional como um conjunto de nações, e não como um conjunto de Estados, como habitual. A doutrina de Mancini repousava em três pilares: a nacionalidade, a liberdade e a soberania. Além disso, Mancini abandonou o princípio da territorialidade para adotar a universalidade das relações privadas, embasando a concepção universalista da cooperação jurisdicional.

Palavras-chave: Relações Internacionais. Cooperação Jurisdicional. Pasquale Stanislao Mancini.
Abstract: This paper aims to analyze the historical evolution of the Privete International Law, particularly the ideal of jurisdictional cooperation between the Middle Ages and Modernity. The paper analyzes the theory of Pasquale Stanislao Mancini, with his notion of the international community as a set of nations, and not as a set of states, as usual. The doctrine of Mancini was based on three pillars: nationality, freedom and sovereignty. In addition, Mancini left the territoriality principle to adopt the universality of private relations, basing the universalist conception of jurisdictional cooperation.

Key words: International Relations. Jurisdictional Cooperation. Pasquale Stanislao Mancini.

1 Possui Pós-doutorado pela Université Paris I (Panthéon-Sorbonne). Doutor em Direito Internacional pela Universidade Luigi Bocconi de Milão. Mestre em Direito e Política da União Europeia pela Universidade de Pádua. Professor de Teoria e História do Direito Internacional nos cursos de graduação, mestrado e doutorado em Direito da Universidade Federal de Santa Catarina.E-mail: arnodalri@gmail.com.

2 Mestre em Direito e Relações Internacionais pela Universidade Federal de Santa Catarina (UFSC). Bacharel em Direito pela Universidade Federal de Santa Maria (UFSM). Professor do Curso de Direito do Complexo de Ensino Superior de Santa Catarina (CESUSC). E-mail: juniorpozzatti@gmail.com.

Recebido em: 06/02/2012.

Revisado em: 25/08/2012.

Aprovado em: 04/10/2012. 


\section{Introdução}

As comemorações em torno dos 150 anos do nascimento do Estado italiano têm comportado uma importante releitura crítica de grande parte dos escritos dos juristas que nos anos do Risorgimento ${ }^{3}$ contribuíram para consolidar a existência daquele como sujeito de direito na Comunidade internacional. Emerge de modo relevante, neste contexto, a teoria desenvolvida pelo jurista e político Pasquale Stanislao Mancini que, no âmago das doutrinas italianas do período, contempla o princípio da nacionalidade como fundamento do direito internacional.

O quadro em que Mancini insere a sua doutrina da nacionalidade imprescindível para a realização desta última -, tem sido, porém, pouco abordado ${ }^{4}$.

Passados quase dois séculos, os feixes de relacionamento no âmbito internacional entre pessoas, empresas e Estados ${ }^{5}$ tornaram-se extremamente mais intensos e complexos em relação ao momento histórico vivido pelo jurista italiano, apresentando demandas cada vez mais articuladas aos sistemas de cooperação internacional e ao direito internacional privado. Como é notório, esse fenômeno globalizante conduziu a um incremento das relações comerciais e contratuais entre partes localizadas

3 Entre os mais significativos juristas do período do Risorgimento italiano, além de Pasquale Stanislao Mancini, podem ser citados Giuseppe Mazzini, Pellegrino Rossi, Daniele Manin, Giacomo Durando, Giovanbattista Giorgini Amedeo Melegari e o conde Camillo Benso di Cavour, este último sendo artífice, juntamente com Giuseppe Garibaldi e com o rei Vittorio Emanuele II, da unificação italiana. Uma extensa e completa lista pode ser encontrada no texto da conferência ministrada em 1911 por Vittorio Scajola, posteriormente publicada em Scajola (1936, p. 1). Ver também: Giorgini (1861).

4 Entre os recentes ensaios dedicados ao tema, ver: Dal Ri Jr. (2011), Nuzzo (2007, p. 161), Colao (2001, p. 259) e Jayme (1988).

5 Neste quadro, a ausência de quaisquer limites ao sistema capitalista de organização social parece criar estruturas econômicas que há muito desafiam as fronteiras estatais. A busca pela maior lucratividade diluiu as etapas de produção de um produto em diversos países do globo, mesmo que isso se dê à custa da violação de direitos humanos. Da mesma forma, as empresas mundialmente atuantes se tornaram tão influentes politicamente que muitas vezes menosprezam a postura do Estado nacional como financiador do desenvolvimento organizado de uma população. 
em diferentes países. As trocas comerciais tendem, assim, cada vez mais a não se limitarem às fronteiras nacionais outrora impostas por razões logísticas ou de política externa dos países, construídas sobre o paradigma do Estado-Nacional ${ }^{6}$.

Trata-se de um fenômeno de flexibilização da soberania estatal que, na prática, do ponto de vista jurídico, se materializa por meio da cada vez mais rápida e crescente interlocução entre sistemas jurídicos nacionais. Esta última é efetivada por mecanismos de cooperação jurisdicional, que nada mais são do que firmes - burocráticos, melhor dizendo - instrumentos processuais que fazem com que a jurisdição nacional se comunique com a jurisdição estrangeira, ou alienígena, no dizer da doutrina privatista pátria.

6 A crescente facilitação nas trocas comerciais entre os Estados ou entre particulares de Estados diferentes, além da própria mobilidade humana, fomentada pelas migrações individuais em busca de melhores condições de vida, muito corriqueiro nesse início de século XXI, está diretamente associada à flexibilização do conceito de soberania dos Estados, tanto explorada pela doutrina jurídica e política contemporânea. Ocorre que, tanto quanto há o crescimento da interlocução entre entes de diferentes países, também há o aumento da litigiosidade e de fatos jurídicos sedentos pela apreciação dos sistemas judiciais ainda essencialmente nacionais, sendo que os responsáveis pela prestação jurisdicional - gerados em ambientes estritamente positivistas - são chamados a atuar nesse novo cenário. Cada vez mais a prestação jurisdicional - edificada sobre os cânones do direito piramidal, estatalista, que desconsidera a complexidade do processo legislativo para reduzi-lo apenas à experiência parlamentar estatal - tem de resolver demandas concretas que transbordam o sistema jurídico nacional. A prestação jurisdicional parece ter chegado, então, ao mais alto nível de complexidade até então alcançado, demandando a construção de um direito cuja eficácia necessariamente ultrapasse as fronteiras nacionais. Segundo Valadão (1978, p. 67), nesse sentido, “[...] o desenvolvimento e a intensidade sempre maiores da vida humana fazem com que várias relações sociais escapem de sua sincronização habitual à lei de um lugar, grupo ou tempo e incidam na órbita doutras leis, vindo a ficar em contato com mais de uma de tantas ordenações jurídicas espaciais e temporais, autônomas e divergentes, que existem no mundo". Tais conflitos de leis ocorrem com frequência crescente, dada a intensificação das relações entre pessoas de todo o mundo, quer na atividade comercial, quer na vida familiar, em consequência da solução de problemas de validade de atos jurídicos praticados sob o império de legislação diferente da solução do lugar onde devem produzir efeito. Problemas semelhantes podem surgir em relação às consequências penais de atos ilícitos praticados sob jurisdição estatal diferente. 
Mesmo estando inseridos em um ambiente típico do século XIX, e a ele pertencendo, os escritos de Pasquale Stanislao Mancini em matéria de direito internacional privado parecem abrigar reflexões que antecipam respostas ao complexo momento vivenciado na atualidade. A convicção do autor de que, em razão da "natureza das coisas e da sobredita comunhão jurídica do mundo inteiro", existiriam verdadeiros deveres internacionais de cooperação jurisdicional, e não simplesmente atos de recíproca cortesia e conveniência, testemunha este fenômeno.

\section{Antecedentes Doutrinários Sobre o Ideal de Cooperação no Âmbito do Direito Internacional Privado}

O modelo de organização baixo medieval, baseado, sobretudo, na fragmentação do poder político em cidades autônomas ${ }^{7}$, fazia com que cada uma possuísse o seu peculiar conjunto normativo - os estatutos das cidades, autônomos e independentes em relação aos demais ${ }^{8}$, formados, sobretudo, pela compilação dos costumes locais (POSENATO, 2005, p. 256). Trata-se de um sistema de fontes que se caracterizava por não prever a priori qualquer tipo de hierarquia entra elas, devido à ausência de uma estrutura centralizada, compacta, unitária como a estatal, destinada a surgir somente alguns séculos depois, com a Modernidade9 (GROSSI, 2010, p. 33). Tem-se, então, um

[...] entrelaçar de autonomias entre ordenamento universal e ordenamentos particulares, entre ius commune e iura propria, que a au-

7 Sobre o papel político das cidades autônomas medievais, ver: Costa (2007, p. 559). Ainda, sobre questões político-jurídicas da cidade medieval, ver: Gilli (2011); Capitani (1979, p. 3-57); Fleckenstein (1980); Waley (1980); Rossi (1987); Heers (1990); Vallerani (1994, p. 165); Dilcher (1996) e Nicholas (1997).

8 A respeito da organização jurídica medieval, ver: Savigny (1831); Coing (1973); Calasso (1954); Cavanna (1982); Grossi (1995) e Ellul (1999).

9 Para Paolo Grossi (2010, p. 33), tal hierarquia das fontes significaria um fenômeno totalmente estranho ao sistema jurídico medieval: “[...] legalismo, ou seja, identificação do direito em lei, em vozes respeitáveis do titular da soberania inserido no ápice da escala hierárquica. Hierarquia das fontes significa perfeita identidade entre ordem política e ordem jurídica, com um direito reduzido a espelho do Estado". 
sência do Estado e a ausência de uma soberania especular ao Estado têm providamente permitido. (GROSSI, 2010, p. 38)

Como é possível imaginar, em um contexto "entrelaçado", mas também bastante atomizado, era frequente que a aplicação dos estatutos comunais gerasse conflitos significativos, podendo dois ou mais deles, cada um com diferentes respostas jurídicas, ser aplicados a um mesmo suporte fático. $\mathrm{Na}$ forma como frequentemente eram confeccionados e colocados em vigor, os estatutos não eram nem absolutamente pessoais, nem absolutamente territoriais (MEIJERS, 1934, p. 592). Essa natureza híbrida, presente em medidas bastante diferenciadas no grande mosaico de cidades autônomas medievais, acentuava ainda mais a problemática, gerando infinitos conflitos, boa parte desses objetos da especulação de diferentes grupos de estudiosos do período.

A partir do século XII, quando muitas cidades europeias - entre elas Veneza, Bolonha, Gênova, Florença, Barcelona, Montpellier - passaram a ter suas economias impulsionadas por um próspero comércio, fenômeno considerado novo nas dinâmicas da idade medieval, as questões envolvendo a aplicação dos estatutos comunais aumentaram consideravelmente, transformando-se em um objeto de estudos ainda mais relevante para o estamento dos juristas. (DAL RI JR., 2004, p. 47)

As escolas de matriz estatutária nascem, neste contexto, tentando fornecer respostas ao impacto da autonomia das civitas nas relações jurídicas entre elas, assim como nas relações jurídicas entre indivíduos e entidades de natureza privada, ligados a diferentes cidades autônomas ${ }^{10}$,

10 Nesta perspectiva, “[...] o jurista defendia a existência de uma gama infinita de iurisdictiones, desde aquela mínima, exercida pelo proprietário dentro dos confins da própria terra até a máxima, exercida pelo imperador em todo o mundo. Portanto sustentava [Bartolo] que no âmbito de cada ordenamento e das suas relativas necessidades, esta iurisdictio é plena e possui em si mesma o próprio regulamento. Assim justificando a pluralidade de ordenamentos jurídicos [...]. A teoria de Bartolo tenta justificar uma diversidade real buscando resgatar uma unidade que não existe somente em razão da fé religiosa ou da submissão à autoridade do Imperador, mas da observância do Direito Romano ou, mais precisamente, do Direito Comum: tais civitas não reconhecem a efetiva autoridade política e pessoal do Imperador e dos seus representantes, mas a indiscutível validade do Direito Comum, ou direito do Império". (LUPI; DAL RI JR., 2005, p. 258) 
realizando uma espécie de articulação entre os diversos estatutos, de forma a delimitar o campo de aplicação deles (MEIJERS, 1934, p. 568). As primeiras dessas escolas podem ser encontradas em território italiano, a partir do século XIII e XIV ${ }^{11}$. Posteriormente, a historiografia jurídica identificou grupos de juristas envolvidos em reflexões similares também na França, durante o século XVI, e na Holanda, no século XVII.

O método estatutário, em síntese, consistia na aplicação do conteúdo normativo de um determinado estatuto no âmbito de cada uma das cidades autônomas, sendo que cada estatuto indicava em quais casos era impreterível a aplicação das suas próprias normas em matéria de relações externas de natureza privada, assim como, ao contrário, em quais casos específicos era permitida a aplicação de normas alheias. Trata-se de um método que não dispunha de regras de conflito $^{12}$, resolvendo, portanto, a questão fática de modo direto, dando pouca ênfase às relações jurídicas em si, pouco se preocupando com a justiça material da decisão, apenas verificando o alcance de um determinado estatuto. (POSENATO, 2005, p. 260)

Do mesmo modo como o método estatutário, o método conflitual surgiu na baixa Idade Média, dessa vez, por obra de juristas ligados predominantemente à Universidade de Bolonha. O trabalho deles era voltado, sobretudo, à elaboração de fórmulas para a resolução de conflitos surgidos da colisão de regras oriundas dos estatutos das cidades autônomas italianas. Especificamente, a colisão de regras estava, na maioria dos casos, relacionada a conflitos comerciais entre negociantes locais e mercadores provenientes de outras cidades autônomas, cujas ações encontravam-se submetidas a normas de direito privado diferentes daquelas da cidade que os hospedavam. (ARAÚJO, 2006, p, 34)

Diferente do método estatutário, o método conflitual apresentava como particularidade a existência de uma norma direcionada a reger o conflito, gerando, com isso, possíveis soluções para questões de direito

\footnotetext{
11 Dentre elas, a escola de Bartolo de Saxoferrato. Ver sobre o jurista: Woolf (1962).

12 Os comentadores eram quem aplicavam o método estatutário. Analisando o conteúdo das ditas leis, verificavam se elas possuíam ou não elementos de extraterritorialidade, e se deveriam ser aplicadas fora das comunas. A ação desses juristas, portanto, era voltada a determinar o âmbito de aplicação das leis.
} 
por meio da designação daquela que seria a lei aplicável, através da utilização da norma indireta. A regra de conflito, neste contexto, não teria por fim resolver a questão material, mas indicaria qual deveria ser o direito aplicado na solução da questão fática.

Em comum, entre as duas escolas, encontrava-se, justamente, como visto há pouco, a busca de soluções para litígios que, surgindo com cada vez mais frequência, manifestavam evidentes elementos jurídicos de conexão exterior, extrapolando os limites das cidades autônomas.

Com os processos de centralização do poder nas mãos dos soberanos e a gradual diminuição do grande mosaico político medieval, o contexto que estimulou o surgimento das duas escolas passa a perder força. Trata-se de um fenômeno lento, mas incisivo, que em alguns casos se estenderá até as últimas décadas do século XVIII ${ }^{13}$, tendo o seu ápice na derrocada do Ancien Régime. Mesmo, contudo, estando em franca decadência ao longo desses séculos modernos, é possível encontrar em algumas realidades europeias a aplicação alternada das fórmulas dos juristas medievais, dependendo dos casos e dos contextos em que eles se apresentavam.

Foi, sobretudo, o surgimento das primeiras ordenações e, posteriormente, dos processos de codificação ${ }^{14}$ que, no interior desse processo, fragilizou o uso dos métodos medievais. Os projetos de codificação do direi-

${ }^{13}$ Nas linhas de Paolo Grossi (2005): "Até 1789 tinha se arrastado, sempre mais fatigosamente e sempre mais se atenuando, um modelo de entidade política como realidade complexa e plural que descendia diretamente da grande forja medieval, uma realidade que se tornou unitária e compacta no férreo estreito - jacobino por primeiro, napoleônico, após - que exigia o 'social' inteiramente controlado pelo 'político"'.

${ }^{14}$ Como explica Paolo Grossi (2007, p. 89), os diversos processos de codificação acontecidos na europa moderna tentavam cada vez mais dispor em poucas normas toda a complexidade do direito privado, reduzindo boa parte do direito consuetudinário até então existente e dos estatutos a um corpo de leis soberanas: "O código quer ser um ato de ruptura com o passado: não se trata de uma fonte nova ou de um novo modo de conceber e confeccionar com profundidade e amplitude a velha ordonnance real; trata-se, ao contrário, de um modo novo de conceber a produção do direito, e desse modo, o inteiro problema das fontes, assim como o problema primário da conexão entre ordem jurídica e poder político". 
to privado do final do século XVIII e do início do século XIX ${ }^{15}$, gerados em mentalidades forjadas no laboratório do jusnaturalismo iluminista ${ }^{16}$, pretendiam, em particular, "[...] realizar a redução de toda a experiência em um sistema articuladíssimo e minuciosíssimo de regras escritas, contemplando todos os institutos possíveis" (GROSSI, 2007, p. 99). Como fruto direto desse fenômeno, pode-se constatar o delineamento de novos métodos para a solução de conflitos com elementos de conexão internacional, que, em boa parte, estavam marcados por um rígido estatalismo ${ }^{17}$.

Impulsionado pelos contrastes oriundos entre teorias antigas e novas, em uma Alemanha que buscava sua unificação política e jurídica, o jurista Friedrich Carl von Savigny ${ }^{18}$ na metade do século XIX propôs um método de solução para a colisão de normas de direito privado no âmbito internacional com elementos bastante inéditos que se aproximam dos utilizados nos atuais sistemas de direito internacional privado. Tal método baseava-se, em síntese, na busca de um conjunto de normas com validade

15 Entre eles o Código Civil italiano, de 1866, e o Código Civil alemão, de 1896. Sobre a lógica que movia os processos de codificação europeus séculos XVIII e XIX, ver: Cappellini (2002); Cappellini; Sordi (2002); Cappellini (2007); Caroni (1998); Cavanna (2005); Tarello (2008) e Viora (1967).

16 "O Código leva consigo, bem penetrado na sua estrutura óssea, a marca da grande antítese jusnaturalista, a mais grave e pesada antítese do direito moderno. Na nova cultura secularizada, a convicção na capacidade do novo sujeito de ler a natureza das coisas passa a ser acompanhada por um problema que a velha cultura medieval e pós-medieval pôde ignorar: quem possui legitimidade para ler a natureza das coisas e dessas extrair regras normativas?”. (GROSSI, 2005, p. 94)

17 Além de ser um marco legislativo, a maior importância do Código Civil francês foi o impulso que deu em outros Estados do mundo civil a seguir o exemplo da França e reunir as diversas normativas que compunham a legislação vigente e construir uma codificação única, válida em todo o Império. Hoje, praticamente todos os países possuem os seus Códigos próprios, nos quais se elevam regulamentações bem diversas e disformes para as diversas temáticas da família, das coisas etc.

18 Savigny nasceu em Frankfurt em 1779 e morreu em Berlim no ano de 1861. Em 1835 começou a elaborar seu trabalho sobre Direito romano contemporâneo, publicando o System des heutigen römischen Rechts (Sistema de Direito Romano Atual), em 8 volumes, escritos entre 1840 e 1849 . Por este trabalho ele foi considerado o fundador do moderno Direito Internacional Privado. O oitavo volume do "Sistema do direito romano atual [...]" pode ser considerado como um dos tratados que mais influenciou o desenvolvimento da matéria. 
universal, passíveis de serem aplicadas pelos mais diferentes ordenamentos jurídicos, dos mais distantes rincões da terra. Já no momento em que foi lançada e nas décadas que se seguiram, a proposta de Savigny adquiriu um significado relevante no mundo jurídico, uma vez que, até então, os sistemas jurídicos eram pensados exclusivamente para si e a partir de si, excluindo dos seus dispositivos internos qualquer tipo de preocupação com as relações exteriores de natureza privada.

As concepções universalistas que caracterizam tal método se devem, sobretudo, ao fato de o autor entender que, ao manterem estreitas relações entre si, as nações formariam uma comunidade internacional. $\mathrm{Na}$ prática, tais relações se concretizariam por meio do ascendente comércio entre o que o jurista alemão considerava serem "os diversos povos da terra". Nas palavras do autor,

[...] quanto mais as relações entre os diferentes povos forem numerosas e ativas, tanto mais se deve estar convencido de que é necessário renunciar ao princípio da exclusão para adotar a ideia da comunidade de povos. (SAVIGNY, 2004, p. 49)

Sofrendo o influxo de tais concepções, a própria ideia de "Nação" presente nos escritos de Savigny aponta para um redimensionamento do papel do Estado na Comunidade internacional ${ }^{19}$, rompendo, assim, com as tradições contratualista e iluminista. Trata-se de um uso novo do conceito de "Nação" que oferece diferentes contornos em relação a alguns postulados da filosofia política que até então condicionava o direito internacional moderno.

Justamente por se valer do flexível conceito de "Nação" - e não daquele rígido de "Estado" -, a proposta de Savigny tornará possível fazer das fronteiras linhas mais porosas e elásticas ${ }^{20}$, proporcionando o surgi-

\footnotetext{
19 Sobre a concepção de "Nação" no Iluminismo e na Revolução Francesa, ver Costa (2000, p. 22).

20 Mesmo valorizando o elemento "Nação" de modo a romper com as tradições jurídicas anteriores, Savigny não chega a contrapô-lo abertamente àquele do Estado enquanto sujeito do direito internacional, como o fará, ainda naquele século, o italiano Pasquale Stanislao Mancini.
} 
mento de um ambiente propício para a formulação de ideias de cooperação internacional entre os Estados em matéria de relações privadas ${ }^{21}$.

A ideia de Comunidade internacional fornecida por Savigny também comportava significativas diferenças em relação à tradição jurídica anterior. Nessa nova perspectiva, ela passava a ser formada por nações que mantinham estreitas relações entre si, sendo necessário entre elas um sistema de normas que afrontasse os problemas de conflitos de leis com um espírito comunitário, evitando que os estrangeiros fossem tratados de forma desprivilegiada. Tal fenômeno faria com que as decisões dos tribunais de diferentes Estados viessem a avaliar uma relação jurídica sempre de uma mesma forma, independente do Estado em que se deram as relações fáticas ${ }^{22}$.

${ }^{21}$ Da maneira como foi construído, o conceito de "Nação" de Savigny parte do pressuposto de que o fenômeno jurídico possui seu conteúdo moldado pela "consciência moral", pelo espírito e pelos costumes do povo que o origina. A noção de "consciência moral", como elemento fundamentador do direito interno, é um dos primeiros aspectos dessa teoria que, retornando à ciência do direito internacional já na segunda metade do século XIX, teve nela um desenvolvimento importante, sendo entendida acima de tudo como "[...] consciência jurídica comum das gentes cristãs". Ver a respeito Savigny (1849, p. 33). Posteriormente, nas últimas décadas do século XIX, alguns discípulos de Savigny deram continuidade ao desenvolvimento dessa noção, inserindo-a, também, no âmago do Institut de droit internacional. É o que acontece, por exemplo, com Johann Caspar Bluntschli, na obra Das moderne Völkerrecht des civilisierten Staaten als Rechtsbuch dargestellt de 1872. Ver a respeito Koskenniemi (2001, p. 45). Vale citar ainda que, nesse âmbito, pode-se encontrar um dos raríssimos pontos de acordo entre as teorias jurídicas de Savigny e de Hegel, já que, este último, também concebia o direito como fruto da evolução dos costumes e do espírito de um povo. Ambos pensadores desenvolveram as suas teorias utilizando-se amplamente de conceitos como "Volksgeist" (espírito do povo) e "Objektive Geist" (espírito objetivo). O "Objektive Geist" serviria para aperfeiçoar e clarificar o "Volksgeist", consistindo no "espírito" de um determinado povo intimamente formado no sangue e no objetivo. Na leitura de Renato Treves, Savigny contemplava o direito como sendo algo com "[...] un contenuto conforme alla coscienza morale, allo spirito e ai costumi del popolo [...]", e este, consciente ou inconscientemente, seria "[...] il prodotto d'una comunità che è della stessa natura dei singoli e che ad essi oppone il proprio volere e la propria incondizionata autorità". (TREVES, 1999, p. 216)

${ }^{22}$ Apresentação de Arno Dal Ri Junior à edição brasileira de Sistema do Direito Romano Atual, de Friedrich Carl von Savigny (2004, p. 11). 
Para chegar a essa uniformidade no tratamento das questões fáticas, as relações jurídicas deveriam passar a se revestir de uma importância fundamental na aplicação do direito internacional privado, devendo ser classificadas de forma sistemática pelos diversos ordenamentos jurídicos. A lei aplicável a um caso com elementos de estraneidade deveria, portanto, ser a lei da sede da relação jurídica. Com isso, o autor afirmava que não deveria ser a norma a determinar a lei aplicável, mas sim a relação jurídica em si que deveria determinar esta última. (CATELLANI, 1902, p. 114 ss.)

As relações jurídicas deveriam, então, no caso de conflitos de leis, serem julgadas da mesma maneira por diferentes tribunais, sem que fosse levada em consideração a localidade de emanação da decisão, já que a lei da relação jurídica não mudaria de um lugar para o outro. Desse modo emerge, em Savigny, o pressuposto de que todo direito é poder pertencente à pessoa e não ao território. Consideradas, portanto, como atributos da pessoa (SAVIGNY, 2004, p. 38), as relações jurídicas deveriam ser apreciadas da mesma forma pelos distintos ordenamentos, sem que fossem submetidas qualquer tipo de alteração em decorrência do lugar em que se realizam. (SAVIGNY, 2004, p. 42)

A formulação desse princípio passava pelas ideias de igualdade dos sistemas jurídicos e de igualdade das pessoas nacionais e estrangeiras (GUTZWILLER, 1929, p. 253-254.). Esta última seria, ainda para Savigny, o objetivo do direito internacional privado ${ }^{23}$. É nesses termos que o autor atribuiu ao seu método uma aplicação universal, ou seja, afirmando que a uniformidade na aplicação do direito internacional privado deveria abranger toda a comunidade de direito entre os povos. Essa igualdade de tratamento para um mesmo fato jurídico é a base do universalismo da teoria de Pasquale Stanislao Mancini.

${ }^{23} \mathrm{O}$ método savignyano partia da relação de fato para determinar qual a lei, de qual território, deveria incidir no caso concreto. Para isso, o autor faz uma divisão das diferentes categorias do direito civil, como as relações contratuais, em que eram aplicadas as regras de direito internacional privado concernentes ao lugar de execução do contrato, que seria a sede do contrato, por exemplo. Essa divisão das diversas categorias do direito civil, conforme as diversas relações jurídicas, permanece até os dias atuais. 


\section{Mancini e a Noção de Comunidade Internacional como um Conjunto de Nações}

Seguindo os passos da teoria de Savigny, a obra do jurista italiano Pasquale Stanislao Mancini ${ }^{24}$ pode ser apresentada como a primeira contribuição sistematizada sobre o princípio da nacionalidade na nascente ciência do direito internacional. No que concerne ao universalismo, entretanto, a teoria de Mancini $^{25}$ se difere daquela do jurista alemão. Tal fenômeno assim ocorre devido ao fato de Savigny trabalhar, sobretudo, com a relação de fato, enquanto Mancini dava ênfase à norma jurídica ${ }^{26}$.

Nas premissas da teoria do autor italiano, não haveria diferenças entre direito internacional público e direito internacional privado, já que o direito internacional privado ${ }^{27}$ possuiria também um caráter público (CATELLANI, 1902, p. 168). Os princípios básicos do direito internacional privado estariam, então, consubstanciados no direito internacional público, e, assim sendo, teriam validade universal (CATELLANI, 1902, p. 152). Por esse viés, a aplicação do direito estrangeiro seria obrigatória para os juízes em todos os países, decorrendo tal obrigatoriedade dos princípios do direito internacional.

24 Político, jurista e professor nas Régias Universidades de Nápoles, de Roma e de Turim, Pasquale Stanislao Mancini nasceu em Castel Baronia, em 1817, e morreu em Nápoles, em 1888. Foi Ministro da Instrução Pública (1862), da Justiça (1876) e dos Negócios Exteriores (1881) do Reino da Itália. Influenciado pelas obras de Gianbattista Vico e de Hugo Grotius, publicou, em 1873, o livro Diritto Internazionale, no qual apresenta a sua teoria sobre a nacionalidade. Outras obras importantes foram: "L'Abolizione della Pena di Morte” (1873), "Sommi Lineamenti di una Storia Ideale della Penalità " (1874), "Della Vocazione del nostro Secolo per la Riforma e la Codificazione del Diritto delle Genti” (1874), “Questioni di Diritto” (1878), "Discorsi Parlamentari” (1893-97).

25 O jurista italiano Pasquale Stanislao Mancini (1817-1888) é considerado um dos principais doutrinadores do direito internacional privado no século XIX. Advogado e professor universitário, Mancini foi também Ministro da Instrução Pública do Reino da Itália (1862), Ministro da Justiça (1876-1878) e Ministro das Relações Exteriores da Itália (1881-1885).

26 Por ter resgatado elementos do método estatutário, o jurista italiano também ficou sendo conhecido como o pai da doutrina "neo-estatutária". Ver a respeito: Catellani (1902, p. 158).

27 Essa afirmação fica claro em Mancini (1876). 
Uma das razões da presença de tal preocupação decorre do fato de que, na época em que o autor escrevia, em pleno século XIX, iniciava-se o processo que iria realizar a unificação política da Itália, cuja península encontrava-se, ainda, até aquele momento, retalhada em diversos principados e em pequenos Estados, quase todos de origem medieval. Justamente por ser partidário da unificação italiana, o jurista afirmava que, no direito internacional, seria a "Nação" a categoria analítica a ser levada em conta (COLAO, 2001, p. 259 ss.), e não o Estado (GUTZWILLER, 1929 , p. 367) ${ }^{28}$. Partindo desse pressuposto, sempre impulsionado pelos pensadores que lançaram as bases do Risorgimento ${ }^{29}$, o jurista exaltava essa nova ideia de "Nação", sustentando que ela deveria tomar para si a condição de protagonista do direito no cenário internacional, lançando sua força de entidade natural contra a artificialidade daquele que, até então, por muitos era considerado o sujeito por excelência: o Estado.

Caracterizada por uma forte apologia dessas "individualidades" formadas por agregações humanas, a teoria de Mancini indica de modo claro as "Nações" como os verdadeiros sujeitos de direito internacional. Trata-se de uma nova ideologia unificadora que, baseada na ideia de nacionalidade, faz com que a "Nação" passe a ser vista como portadora de uma individualidade própria, sendo considerada como sujeito político determi-

28 Para Mancini, segundo Carlo Curcio (1950, p. 156), o Estado que existia até então "[...] era contro natura, era soltanto un atto di forza, era, anzi, il governo stesso. Spostando, invece, il fondamento del diritto pubblico interno ed Internazionale dallo Stato alla Nazione, Mancini non solo riteneva di assicurare una legittima ed organica costituzione politica e sociale interna ai singoli popoli, ma era sicuro di fondare un sistema di relazione pacifiche internazionali".

29 Do ponto de vista filosófico, vê-se, sobretudo, o influxo do romantismo europeu, fazendo com que o estilo literário e poético evidenciado nos escritos dos juristas que a esse movimento pertencem encontra-se "[...] em todo o movimento do Risorgimento. Envolvida no romantismo que dominava a literatura, a idéia de uma nação italiana ganha vida própria e contornos antropomórficos, contrapondo-se à ocupação de Estados estrangeiros como a Espanha, a França ou a Áustria, que desde a baixa Idade Média, e de um modo mais forte após o Congresso de Viena de 1815, mantiveram retalhada, mediante intervenções diretas ou indiretas, a península”. Ver a respeito: Dalri Jr. (2011). Com referência específica ao Risorgimento como fenômeno político e cultural, ver Banti (2004). 
nante na Comunidade internacional ${ }^{30}$. Nas linhas de Mancini, o protagonismo desses grandes agrupamentos humanos interligados por traços comuns nos âmbitos cultural, étnico, linguístico e religioso, era fortemente exaltado, transformando-os em sujeitos de direito, em clara oposição ao papel até então outorgado aos Estados ${ }^{31}$.

O Estado, portanto, somente se constituiria a partir do momento em que a "Nação" iniciasse o seu processo de organização política, em uma segunda etapa da vida da coletividade humana, momento em que esta última já se reconhecesse como detentora de sua própria individualidade por meio de elementos historicamente bem definidos.

O amplo quadro que se delineia, na qual se contempla uma comunidade internacional composta por nações ao invés de Estados, conduz o jurista italiano reiterar a relevância da resolução do conflito entre elas por meio de mecanismos de cooperação jurisdicional. Tais mecanismos seriam importantes já que somente a "Nação" seria a entidade apta a refletir a religião, a cultura, a língua, os elementos que cada indivíduo carregaria consigo, estivesse onde estivesse (GUTZWILLER, 1929, p. 366), demarcando a ligação entre ele e o ordenamento jurídico da "Nação" a qual pertence. Conforme leciona Erik Jayme (1988, p. 75) ${ }^{32}$ :

30 Giuseppe Mazzini, personagem emblemático do processo de unificação italiana, pode bem representar este período de debates de caráter eminentemente ideológico sobre o protagonismo da "Nação" nas esferas política e jurídica. A proposta de Mazzini tinha origens em um cosmopolitismo próximo ao iluminista, partindo do pressuposto de que esta nova "Nação" deveria ser universal e democrática, composta por homens que "[...] formam um só grupo, reconhecem um mesmo princípio, e se voltam, sob a égide de um direito comum, à obtenção de um mesmo fim”. Ver Mazzini (1908, p. 123).

31 Em 1851, em conferência ministrada em Turim, tendo por título "Del principio della nazionalità come fondamento del diritto delle genti", o autor apresenta publicamente esta tese, fundamentada na afirmação de que, na gênese do direito internacional, a "Nação" representaria a unidade elementar, a mónada racional da ciência. A conferencia foi ministrada quando Mancini tomou posse da primeira cátedra universitária italiana dedicada ao direito internacional, na Universidade de Turim, em 22 de janeiro de 1851. Foi publicada posteriormente no volume Diritto Internazionale. Prelezioni (Napoli, 1873). A mesma obra foi recentemente traduzida e publicada no Brasil, em Mancini (2003).

32 Entre os autores contemporâneos, que utilizam elementos da teoria de Mancini, está o jurista alemão Erik Jayme, que pensou o direito internacional privado no século XX e 
No sistema de Mancini, o indivíduo e os seus direitos subjetivos em matéria de direito privado estão em primeiro plano. Da estreita ligação que existe entre o individuo e a nação a qual ele pertence emana a determinação do direito aplicável nas relações jurídicas pessoais. $^{33}$

A concepção de "Nação" historicamente construída, livre de conflitos ideológicos, políticos ou religiosos, mais unida pelo amor à pátria do que pelo ódio às demais nações, contextualiza o jurista italiano entre as correntes idealistas e românticas do século XIX. Trata-se de uma característica que propiciou a absorção de alguns dos principais elementos do universalismo proposto por Savigny no campo do direito internacional privado $^{34}$.

\section{Influências e Nuances na Concepção Universalista}

A pedra angular do universalismo de Mancini encontra-se na afirmação de que os indivíduos seriam os detentores da juridicidade da esfera

\footnotetext{
XXI, de acordo com as características da pós-modernidade. O pensador de Heidelberg entende que, antes de construir uma teoria do direito internacional privado na pósmodernidade, é importante estabelecer quais são os valores e as características dessa pósmodernidade. A identificação desses valores passa, irremediavelmente, pela superação do modelo estatalista de organização social. Após ter sedimentado o conhecimento sobre a pós-modernidade, Erik Jayme diagnosticou a influência da pós-modernidade no direito internacional privado. Ele refundou a clássica compreensão da disciplina, mas agora fundada na prevalência dos direitos humanos, ao invés do império das normas de conflito. 33 "Nel sistema di Mancini, l'individuo e i suoi direitti sogettivi in materia di direitto privato stanno in primo piano. Dallo stretto legame che sussiste tra l'individuo e la Nazione alla quale egli appartiene consegue nello stesso tempo la determinazione del diritto applicabile ai rapporti giuridici personali".

${ }^{34}$ Do ponto de vista da estrita dogmática, a Lei de Introdução ao Código Civil italiano, de 1865 , que entrou em vigor em primeiro de janeiro de 1866, foi a primeira norma jurídica a refletir a doutrina de Mancini no direito internacional privado, quando estabelecia a nacionalidade como elemento determinante do estatuto pessoal do indivíduo. Ver sobre o processo de construção do Código Civil Italiano: Gutzwiller (1929, p. 159).
} 
da qual eram nacionais ${ }^{35}$. Tal perspectiva os apresenta como portadores de um determinado direito, aquele da sua própria "Nação", que os acompanharia para onde eles fossem, mesmo que além das fronteiras do Estado o qual possuem vínculos como nacionais (GUTZWILLER, 1929, p. 367). A "Nação" de um determinado indivíduo, portanto, o acompanharia mesmo quando este último adentrasse as fronteiras de outra "Nação". Por esse motivo, Mancini, à "Nação" que os hospeda, incumbiria a aplicação das regras da "Nação" de origem do cidadão. Trata-se de um fenômeno que se daria em todos os casos que envolvessem o seu estatuto pessoal, em função do princípio da nacionalidade ${ }^{36}$. A única exceção à regra seria concernente às questões de ordem pública. (CATELLANI, 1902, p. 159)

O princípio da nacionalidade, neste quadro, passa a se contextualizar como limite da ação do Estado em relação aos estrangeiros presentes no seu território, fazendo com que seja respeitada, desse modo, a legítima e inviolável autonomia individual recíproca (MANCINI, 1876, p. 32). Tal fenômeno se daria do mesmo modo como, dentro dos limites internos de um Estado, o princípio da liberdade protegia a legítima e inviolável autonomia da vontade individual, impondo um limite à justa ação do poder político dos legisladores e dos governos. Segue justamente, neste sentido, o comentário realizado por Enrico L. Catellani, em 1902, quando examinava a obra de Mancini:

Como a liberdade dos indivíduos não pode sofrer injusta limitação em nome da liberdade dos outros indivíduos cidadãos do seu mesmo país, a liberdade individual não cessa de ser exercitada quando se faz valer fora dos confins do respectivo Estado, isto porque aqueles direitos de ordem privada pertencem ao homem considera-

\footnotetext{
35 Mancini via certa equivalência entre a condição e o direito dos indivíduos no Estado e a condição e o direito das nações no universo. Em cada Estado são as leis de ordem privada que garantem a liberdade individual e as leis de ordem pública que garantem a soberania do território. Sobre o assunto, ver Catellani (1902, p. 158).

36 O moderno direito internacional abandonou o princípio da nacionalidade ao reconhecer que os Estados, e não as nações, são os seus verdadeiros sujeitos, conforme a Carta da Organização das Nações Unidas.
} 
do por sim mesmo, e não como membro de uma sociedade política (CATELLANI, 1902, p. 158) (77 $^{37}$

Disso denota-se claramente que Mancini assentou a sua doutrina na ideia da extraterritorialidade. Assim como Savigny, ele parte do pressuposto de que o direito sempre se refere à pessoa, e não às coisas, concluindo que o direito da "Nação" de origem deveria acompanhar a pessoa nas suas excursões e nas relações para além das fronteiras nacionais. É nessa perspectiva que leciona Erik Jayme, quando afirma que

[...] o princípio informador do sistema de Mancini consiste na modificação da disciplina quanto ao tratamento dos estrangeiros, através da elaboração de um direito "internacional" privado: poderia se dizer, de uma "internacionalização" do direito privado. (JAYME, 1988$, p. 75$)^{38}$

O direito privado seria, portanto, de natureza pessoal e nacional e, como tal, protegeria e acompanharia a pessoa mesmo fora da sua pátria. Diversamente, o direito público seria de natureza territorial, dominando todos os fatos que devem ser realizados sobre um território e, de forma indistinta, todos os homens que nele vivem, sejam naturais ou estrangeiros.

A presença de um nexo entre liberdade, "Nação" e humanidade também é uma das características significativas da teoria do jurista italiano, nesse caso concreto herdada de Giuseppe Mazzini (LOPEZ DE OÑATE, 1944, p. 26; NUZZO, 2007, p. 161). Partindo desse pressuposto, diante da pluralidade de nações, o princípio de nacionalidade somente poderia significar "[...] a igual inviolabilidade e proteção de todas [...]" (MANCINI,

37 "Come la libertà degli individui non può patire ingiuste limitazione nel nome della libertà di altri individui loro concittadani, cosi quella stessa libertà individuale non cessa di esercitarsi legittimamente quando la si fa valere fuori dei confini dello Stato rispettivo; poichè quei diritti di ordine privato appartengono agli uomini come ad uomini e non come a membri di una società politica”.

38 "Il principio informatore del sistema di Mancini consiste nel superamento della disciplina sul trattamento degli stranieri mediante la elaborazione di un diritto 'internazionale' privato: potremmo dire, per effetto di una 'internazionalizzazione' del diritto privato”. 
2003, p. 80), tal princípio seria violado, portanto, “[...] se nossa nacionalidade sofresse da parte das outras injúria e obstáculo a seu livre desenvolvimento" (LOPEZ DE OÑATE, 1944, p. 26; NUZZO, 2007, p. 161). Do mesmo modo aconteceria se a nacionalidade

[...] invadisse o domínio das outras e ofendesse a sua legítima liberdade. Em ambos os casos, a igualdade seria rompida, a independência nacional sofreria danos, o império do Direito seria derrubado. (LOPEZ DE OÑATE, 1944, p. 26; NUZZO, 2007, p. 161) ${ }^{39}$

No escrito "A utilidade de tornar obrigatórias para todos os Estados certas normas de direito internacional privado, para garantir a decisão uniforme dos conflitos entre as diferentes legislações civis e criminais [...]" (MANCINI, 1876, p. 37), emergem ainda outras perguntas e respostas ricas em elementos para a compreensão dos seus objetivos finais. Refletindo sobre como o direito das gentes contempla a existência, em cada uma das soberanias independentes, de um poder absoluto de recusar a aplicação de leis estrangeiras sobre o seu próprio território, Mancini concluiu que o conceito de independência de um Estado não poderia ser exagerado a ponto de não autorizar a aplicação dos direitos de outro Estado, ou refutar-se à cooperação jurisdicional. (MANCINI, 1876, p. 37)

É por isso que, em razão da natureza das coisas e da sobredita "comunhão jurídica" do mundo inteiro, existiriam verdadeiros deveres internacionais nessa matéria, e não simplesmente atos de recíproca cortesia e conveniência. As nações do mundo, nessa perspectiva, não possuiriam um poder legítimo de desconhecer inteiramente a autoridade estrangeira e de não dignar respeito às leis estrangeiras sobre o próprio território. Da mesma forma, as nações não poderiam obrigar as pessoas e as relações jurídicas, que pela própria natureza dependem de leis estrangeiras, a inquinar-se e a submeter-se ao comando incompetente da lei territorial.

\footnotetext{
39 Ainda sobre o tema, dirá ainda Mancini (1988, p. 66): “Um Estado, em que muitas viçosas nacionalidades são sufocadas numa união forçada, não é um corpo político, mas um monstro incapaz de transmitir vida. As nações que não possuem governo saído das próprias vísceras e que servem a leis a elas impostas de fora não têm mais vontade jurídica, já se tornaram meios dos fins de outrem e, portanto, coisas".
} 
Como é possível observar, portanto, Mancini concebe como menos relevante um dos pressupostos básicos da doutrina de direito internacional privado elaborada por Savigny, ou seja, o princípio da territorialidade. Para o jurista italiano, a aplicação das leis estrangeiras, quando por elas devam regular-se as relações jurídicas, não representaria um simples ato de comitas gentium, mas o cumprimento de um dever por parte do Estado. A garantia e o respeito desses direitos privados no exterior seriam:

[...] um dever rigoroso de justiça internacional, ao qual uma nação não pode se subtrair sem violar os direitos das gentes, sem romper a ligação que une a espécie humana em uma grande comunidade de direito, fundada sobre a identidade e sobre a sociabilidade da natureza humana [...] (MANCINI, 2000, p. 140) ${ }^{40}$

Ainda, para Erik Jayme, segundo o ensinamento de Mancini, haveria uma obrigação internacional:

[...] dos Estados de reconhecer aos cidadãos estrangeiros, em matéria de direito privado, os mesmos direitos dos súditos do Estado. Esta obrigação não derivava então, de uma simples comitas: de outra forma. Não estaria sujeito a condição de reciprocidade. (JAYME, 1988, p. 63) $)^{41}$

A soberania de um Estado, desse modo, não poderia ser inflexível a ponto de permitir a violação dos direitos dos outros Estados. A independência recíproca entre os Estados não seria nem mais, nem menos violável do que a liberdade recíproca dos indivíduos. Quanto à dúvida que poderia pairar se a aplicação de leis estrangeiras sobre o território submetido à soberania alheia fundamentar-se-ia em uma livre concessão de cortesia e no consentimento expresso ou tácito das outras nações, ou na “[...] exis-

40 "[...] un devoir rigoureux de justice international, auquel une nation ne peut pas se soustraire sans violer le droit des gens, sans rompre le lien qui unit l'espèce humaine dans un sociabilité de la nature humaine [...]".

41 "[...] obbligo internzionale degli Stati di riconoscere ai cittadini stranieri, in materia di diritto privato, gli stessi diritti dei sudditi dello Stato. Questo obbligo non deriverebbe quindi da una semplice comitas: esso inoltre non serebbe sottoposto alla condizione di reciprocità". 
tência de um dever internacional imposto pelos direitos das gentes [...]", Mancini foi taxativo ao afirmar a segunda hipótese. (MANCINI, 1876, p. 37)

Nessa ótica, a ciência não poderia levar em consideração a aplicação de leis estrangeiras em território alheio senão como o cumprimento de um rigoroso dever de justiça internacional. Todas as nações se encontrariam vinculadas a respeitar tal preceito, afirmando que o descumprimento do mesmo acarretaria em um dano permanente ao vínculo que une os seres humanos em uma comunhão de direito, lesando, assim o direito das gentes. Emerge, por meio dessa reflexão, o caráter universalista da teoria manciniana, assim como torna-se evidente a convicção de que a cooperação jurisdicional deve ser fortalecida. (MANCINI, 2000. p. 140)

Indiretamente, ainda neste âmbito, outro aspecto da concepção de "internacionalidade" manciniana acaba por ser ressaltado:

Um indício da "abertura" de um ordenamento jurídico em direção aos outros ordenamentos - um indício, então, da internacionalidade de um ordenamento jurídico - é constituído pela postura do Estado em matéria de reconhecimento e de execução de sentenças estrangeiras. (JAYME, 1988, p. 63) 42 $^{2}$

Justamente nessa abertura dos ordenamentos jurídicos encontrar-se-ia a condição para se operacionalizar a cooperação jurisdicional necessária para o acesso à justiça no cenário internacional.

\section{Delineando a Cooperação Jurisdicional}

O dever de cooperação jurisdicional da qual falava o jurista italiano se estendia ao tratamento dispensado à homologação de sentenças estrangeiras, comunicação de atos e execução de decisões alhures. Nesse tema,

\footnotetext{
42 ' $U n$ indice della 'apertura' di un ordinamento giuridico nei confronti degli altri ordinamenti - un indice, quindi, della 'internazionalità' di un ordinamento giuridico - è constituito dall'atteggiamento in materia di riconoscimento e di esecuzione delle sentenze straniere".
} 
Mancini faz uma releitura de elementos elaborados pelas escolas medievais italianas, funcionais no sentido de evitar a necessidade de um duplo processo para a atribuição de eficácia às decisões estrangeiras ${ }^{43}$. No dizer de Erik Jayme:

Mancini promove a unificação do procedimento na matéria [de eficácia da sentença estrangeira], sustentando que o controle das sentenças estrangeiras com vistas a sua execução no interior do Estado deveria ser limitado a poucos aspectos formais, como, por exemplo, a competência internacional do juiz estrangeiro. Mancini se propunha a contrastar o reexame de mérito e falava de: "este simples juízo que se chama delibação". (JAYME, 1988, p. 63-64)

Esse tema vai se inserir, na teoria de Mancini, como um dos seus principais eixos da ideia de universalidade proposta pelo autor. Cada indivíduo carregaria consigo um título para exigir de todos os outros homens a posse reconhecida, segura e garantida daquela medida da própria liberdade, daquela extensão do seu exercício, onde quer que se encontre sobre a terra, e independentemente da autoridade que o governasse. Não seriam, nesta ótica, leis e códigos a gerar direitos e liberdades da criatura humana, mas, ao contrário, eles teriam o dever de reconhecê-los e de respeitá-los de forma adequada, mesmo em relação aos indivíduos estrangeiros. (MANCINI, 1876, p. 13)

Com isso, caso os Estados não aplicassem as leis estrangeiras, eles estariam violando um verdadeiro dever de justiça e infringiriam, concomitantemente, a autoridade do direito das gentes, voltado a garantir o interesse de todos os Estados em ver respeitados e garantidos os direitos e as legítimas liberdades de cada um dos seus membros e cidadãos, in-

43 "Il pensiero di Mancini era ancora influenziato dalla prassi statale medievale dal mutuo reconoscimento automatico delle sentenze; tale prassi evitava la necessità di un doppio processo per la attribuizione di efficacia alle sentenze straniere”.

44 "Mancini promosse l'unificazione della procedura in materia, sostenendo che il controllo delle sentenze straniere in vista della loro esecuzione all interno dello Stato avrebbe dovuto essere limitato a pochi aspetti formali, come ed esempio la competenza internazionale del giudice straniero. Egli si proponeva di contrastare il riesame del merito e parlava di: 'questo semplce giudizio che si appella di delibazione,". 
clusive por outros povos (MANCINI, 1876, p. 13). Tal dever obrigatório de justiça internacional é compartilhado e defendido por todas as escolas italianas de direito internacional que sucedem ao autor. (MEIJERS, 1934, p. 595)

Tal dever internacional deveria, segundo o autor, ser observado por todas as nações da mesma forma, com vistas a produzir o mesmo resultado prático. Trata-se de uma medida mínima a ser tomada no âmbito das obrigações internacionais, muito aquém da qual se encontraria a violação da norma internacional, devendo ser necessariamente a mesma para todas e para cada uma das nações. Nesse contexto, porém, uma questão se coloca - não respondida de modo exaustivo pelo jurista italiano -, ou seja, quais seriam os meios adequados para conduzir as nações a essa idêntica observância e à necessária identidade das normas, em relação ao reconhecimento e à garantia prestada às pessoas, bens e atos estrangeiros?

Mesmo sem que haja uma resposta direta à questão acima, torna-se bastante evidente a convicção do autor de que não existiria outra forma de cessar ou, pelo menos, reduzir em máxima parte as desordens e os perigos de uma situação tão anormal, senão mediante a negociação e a estipulação, entre os vários Estados, de um conjunto de convenções internacionais. Esses tratados seriam voltados sobretudo a regular a cooperação entre as jurisdições e a determinar, com acordos uniformes, poucas, mas precisas, normas convencionais, a fim de tornar obrigatória a aplicação do direito estrangeiro no foro. (MANCINI, 1876, p. 15)

Com isso, o jurista italiano demonstrava entender que o único meio para combater a tendência a não uniformidade advinda das pluralidades de codificações nacionais seria, em primeiro lugar, formar uma doutrina científica suficientemente potente (ARAÚJO, 2006, p. 41) que fosse aceita de modo amplo. Posteriormente, essa mesma doutrina seria consagrada em um sistema de tratados internacionais reguladores da matéria (MANCINI, 1876, p 15). Desse modo seriam excluídos todos os sistemas que, como máxima, negassem qualquer autoridade às legislações estrangeiras, fazendo depender a admissão e o uso das leis estrangeiras em outros territórios unicamente do consentimento da soberania territorial. 
A questão que se coloca nessa linha, então, se refere a como se daria na prática a resolução dos conflitos privados entre as diferentes culturas jurídicas. E a resposta encontra-se, justamente, na consolidação de uma estratégia visando conjuntamente o resgate de elementos do método estatutário e a celebração de tratados internacionais tendo por objeto matéria de direito internacional privado.

Tal estratégia repousaria sobre três pilares, ou seja, a nacionalidade, a liberdade e a soberania. O primeiro pilar dispõe sobre um elemento necessário, ao qual o indivíduo não poderia derrogar com a sua vontade. Era constituído pelas normas que regulamentavam o estatuto pessoal, as relações de família, sucessões, e outras matérias, não podendo ser alteradas ou rejeitadas pela pessoa. Esse primeiro pilar seguia o princípio da nacionalidade, que

[...] vem imerso no sentido de que cada homem, nas suas relações pessoais, deve ser sujeito ao direito da sua pátria de origem, direito a ele proporcional e ao qual tem familiaridade. Assim, ao italiano, quando nasce, se casa ou morre, se aplica o direito italiano; ao alemão, nas mesmas circunstâncias, se aplica o direito alemão. (JAYME, 1988, p. 20) $)^{45}$

O elemento de conexão da nacionalidade passa a ter, portanto, um papel dominante na doutrina em tela (CATELLANI, 1902 p. 129.). Como já mencionado, nesta última, as normas jurídicas que compõem o direito necessário são determinadas pelo clima, pelo ambiente geográfico, pela raça, pelos costumes, pela história e pela religião da "Nação" ${ }^{46}$. Em que pese essas diferenças, a aplicação de leis estrangeiras sobre o território

45 "Viene inteso nel senso che ogni uomo, nei suoi rapporti personali, deve essere sottaposto al diritto della sua patria di origine, diritto a lui commisurato e del quale ha dimestichezza. Cosí all italiano, quand nasce, si sposa o muerre, si applica il diritto italiano; al tedesco, nelle medesime circonstanze, si applica il diritto tedesco".

46 Assim, quando o direito de um povo é diferente do direito de outro, tal fenômeno é o produto da diferença entre esses fatores supraelencados. A partir desse raciocínio, Mancini proclamava a aplicação da lei nacional como princípio fundamental do direito internacional privado, pois a lei nacional reflete as condições da relação jurídica onde surgiu o direito. Ver: Gutzwiller (1929, p. 366). 
submetido à soberania alheia fundamenta-se em um dever internacional imposto pelo direito das gentes, conforme supramencionado ${ }^{47}$. Isso porque

[...] o direito civil privado é pessoal e nacional, e, como tal, deve acompanhar a pessoa mesmo estando fora de sua pátria; o direito público, ao contrário, é territorial: ele plana sobre o território e sobre todos aqueles que o habitam, nativos ou estrangeiros sem distinção. (CATELLANI, 2000. 129) ${ }^{48}$

Ora, sem dúvida, o dever de cooperação jurisdicional também é corolário dessas ideias.

Além do elemento necessário, deve-se considerar também o elemento voluntário. Este é o segundo pilar do método de Mancini: “Ao princípio da autonomia dos entes privados correspondia no direito internacional privado à possibilidade, para o contraente, de escolher a lei aplicada às obrigações contratuais" (JAYME, 1988, p. 75) ${ }^{49}$. Trata-se, aqui, dos direitos que o estrangeiro pode exercitar de acordo com a sua própria vontade. Refere-se aos bens, aos contratos e às obrigações. Nesses casos, o direito internacional privado fica reduzido a indagar a intenção das partes contratantes.

Deriva-se desse segundo pilar o princípio da liberdade, a ser aplicado quando o legislador reconhecesse não estar interessado em introduzir coações inúteis e obstáculos ao exercício da liberdade lícita do estrangeiro. Em matéria de relações jurídicas sujeitas ao direito privado voluntário,

\footnotetext{
47 Assim como cada indivíduo pode reclamar do seu próprio Estado e dos seus concidadãos o respeito do seu patrimônio de direito privado, também ele pode reclamar das outras nações e dos outros Estados um idêntico respeito por esse seu patrimônio. Ver: Catellani (1902, p. 159).

48 "[...] le droit civil privé est personnel et national, et, comme tel, doit accompagner la personne même en dehors de sa patrie; le droit public, au contraire, est territorial: il plane sur le territoire et sur tous ceux qui l'habitent, indigènes ou étrangers sans distinction".

49 "Al principio dell'autonomia dei privati corrispondeva nel diritto internazionale privato la possibilità, per i contraenti, di scegliere la legge applicabile alle obbligazioni contrattuali".
} 
Mancini continua a considerar competente, em princípio, a lei nacional. Mas os interessados podem submeter-se ao direito em vigor num país estrangeiro. É o princípio da autonomia da vontade que ganha espaço (MANCINI, 2003, p. 72), mas balizado pela noção de "ordem pública"

Em Mancini também existem regras limitadoras à autonomia da vontade, quais sejam, aquelas que impedem a afronta aos interesses do Estado no qual o estrangeiro exige a aplicação da sua lei nacional. É, nesse caso, que prevalece a noção de territorialidade, justamente porque, diante da possibilidade de dano ou violação da soberania do Estado que hospeda o estrangeiro, aquele passa a ter plena legitimidade no ato de vedar a aplicação de regras que não são as suas próprias. Trata-se do princípio da soberania, aplicado quando os estrangeiros, em igualdade com os cidadãos, são sujeitos às normas de ordem pública e a todo o direito público do Estado ${ }^{51}$. Trata-se, na construção do jurista italiano, de um princípio de exceção, superior em relação aos demais. Nesse sentido, segundo Erik Jayme:

A ordem pública compreende, ao invés, alguns princípios inderrogáveis do ordenamento social e econômico que se baseiam na soberania do Estado. Entre tais princípios, Mancini inclui também a regra segundo a qual as relações jurídicas relativas a bens imóveis são sujeitos a lei do lugar da situação da coisa: deste modo vinha formulada uma nova norma de conflito. Desde então, à ordem pu-

\footnotetext{
50 Segundo Irineu Strenger, "porordem pública em direito internacional privado, pretendem os jurisperitos designar toda aquela base social, política de um Estado, que é considerado inarredável para a sobrevivência desse Estado. [...] Por ordem pública entende-se um conjunto de princípios implícita ou explicitamente conhecidos na ordenação jurídica que, considerados fundamentais, excluem a aplicação do direito estrangeiro. [...] Essa noção de ordem pública serve, portanto, para guardar a base considerada fundamental, que é subjacente a cada ordenamento jurídico nacional. A doutrina assinala que esse conceito de ordem pública preenche duas funções: 1) impedir que sejam feridos os sentimentos de nacionalidade [...] e 2) não são raros os que acham que essa exceção de ordem pública atua para defender orientação política [...]”. (STRENGER, 2003, p. 102)

51 Para Mancini, o direito público de um Estado é uma espécie de expropriação legítima que o Estado exercita sobre uma parte da liberdade pessoal dos indivíduos protegidos por esse Estado. Vide, CATELLANI (1902, p. 159).
} 
blica, foi, sobretudo, atribuída a função de proteger esses princípios dos quais depende a segurança pública. (JAYME, 1988, p. 20-21) ${ }^{52}$

Com a afirmação do princípio da soberania, Pasquale Stanislao Mancini esgota a apresentação do conjunto de pressupostos fornecidos pela sua teoria sobre a cooperação internacional em matéria jurisdicional.

\section{Conclusões}

A teoria apresentada por Mancini em matéria de cooperação jurisdicional foi alvo de diversas críticas ao longo dos séculos XIX e XX. Alguns doutrinadores sustentaram que essa teoria apresentava elementos subversivos, outros, elementos excludentes, enquanto, ainda outros, chamaram-na de utópica, reconhecendo que a mesma tinha nascido em berço aos anseios unificadores do romantismo que envolvia a época de sua elaboração, sendo, por isso, datada, e em favor do patriotismo italiano (CATELLANI, 1902, p. 130). Independente das críticas é possível constatar que, de fato, o princípio da nacionalidade exercitou uma influência notável sobre o desenvolvimento das doutrinas de direito internacional privado, não só no âmbito da escola italiana, mas da matéria em geral ${ }^{53}$.

O universalismo proposto por Mancini, em particular, obteve importante reconhecimento pela doutrina posterior (AGNELLI, 1991, p.

\footnotetext{
52 "L'ordine pubblico comprende, invece, alcuni princípi inderogabili dell ordinamento sociale ed economico che si basano sulla sovranità dello Stato. Tra tali principi Mancini incluse anche la regola secondo la quale i rapporti giuridici relativi a beni immobili sono sottoposti alla legge del luogo di situazione della cosa: in questo modo veniva formulata una nuova norma di conflito. Da allora, all'ordine pubblico fu supratutto attribuita la funzione di proteggere quei princípi dai quali dipende la sicurezza pubblica”.

53 Em 1928 surgiu o Código Americano de Direito Internacional Privado, mais conhecido como Código de Bustamante, trazendo inúmeras regras de processo internacional. Este foi aceito por diversos países, tendo, inclusive, aplicação nos dias de hoje. Os três princípios da teoria manciniana - Nacionalidade, Liberdade e Soberania - estão claramente delineados no artigo $3^{\circ}$ do Código Bustamante. O critério da nacionalidade foi adotado por muitas legislações nacionais, tendo sido aceito pela grande maioria das codificações Europeias, pelo Instituto de Direito Internacional e pela Conferência de Haia de Direito Internacional Privado, conforme várias convenções por ela patrocinadas.
} 
219), que tributou a essa doutrina o mérito de estabelecer as bases nas quais se assenta a cooperação internacional em matéria jurisdicional. Ainda, mais do que isso, foi reconhecido o relevante papel desempenhado pelo jurista italiano ao projetar um modelo para unificação das normas de direito internacional privado que, até os dias de hoje, é considerado como pleno de vitalidade. (CATELLANI, 1902, p. 167)

Os problemas gerados pelas acirradas disputas de natureza política e econômica acontecidas entre as nações na primeira metade do século $\mathrm{XX}$, na qual se tornou frequente o surgimento de nacionalismos exacerbados - pregando que cada Estado poderia, em nome do princípio da independência política, proibir dentro do seu território toda a violação ao seu direito público e à sua ordem pública -, contribuíram para testemunhar a importância do pensamento do autor italiano.

Não acontece de modo diferente no que concerne às questões nascidas da intensa movimentação humana e mobilidade de bens e fatores de produção que se tem no cenário internacional a partir dos anos cinquenta, em que se multiplicaram de modo extremamente relevante os fatos sociais com conexão internacional. Uma das consequências desse fenômeno tem sido, justamente, o aumento e a diversificação de litígios no âmbito das relações privadas com natureza internacional, sendo que grande parte destes acaba sendo levada perante órgãos judiciários nacionais na espera de uma resolução. Nesse panorama, muitas vezes em aberta contradição com as premissas do pensamento de Mancini - que demonstra ser a aplicação de lei estrangeira em território alheio o cumprimento de um rigoroso dever de justiça internacional -, a prestação jurisdicional continua a ser pautada pela ótica positivista-nacionalista, encontrando significativas arestas para a comunicação com as jurisdições alhures por meio da cooperação jurisdicional.

Como foi possível constatar ao longo deste ensaio, mesmo por cerca de um século e meio após a publicação dos primeiros escritos de Pasquale Stanislao Mancini, o cenário que se apresenta aos nossos olhos continua a salientar a importância dos pressupostos fornecidos pelo jurista. Uma importância que claramente se legitima quando o autor afirma que as doutrinas do direito internacional privado - incluindo aquelas acerca 
da cooperação jurisdicional - são fundamentadas na comitas, no consentimento voluntário das concessões, mas, certamente, também em um dever de diálogo com o elemento jurídico internacional, ou seja, um dever de cooperação jurisdicional.

\section{Referências}

AGNELLI, Arduino. La fortuna di Mancini nel primo novecento. In: ZECCHINO, Ortensio; SPADOLINI, Giovanni (a cura di). Pasquale Stanislao Mancini: L'uomo, lo studioso, il politico. Napoli: Guida, 1991. ARAÚJO, Nádia de. Direito internacional privado: teoria e prática brasileira. Rio de Janeiro: Editora Renovar, 2006.

BANTI, Alberto Mario. Il Risorgimento italiano. Roma: Laterza, 2004. BLUNTSCHLI, Johann Caspar. Das moderne Völkerrecht des civilisierten Staaten als Rechtsbuch dargestellt. 3. auf. Nördlingen: Beck, 1872.

CALASSO, Francesco. Medioevo del diritto. Le fonti. Milano: Giuffrè, 1954.

CAPITANI, Ovidio. Città e Comuni. In: CAPITANI, Ovidio; et al. Storia d'Italia. v. IV. Torino: UTET, 1979.

CAPPELLINI, Paolo. Codici. In: FIORAVANTI, Maurizio (a cura di). Lo Stato Moderno in Europa. Roma-Bari: Laterza, 2002.

CAPPELLINI, Paolo. Sistema jurídico e codificação. Curitiba: Juruá, 2007.

; SORDI, Bernardo (a cura di). Codici: una riflessione di fine millennio. Milano: Giuffrè, 2002.

CARILLO, Gennaro (a cura di). Unità e disunione della polis. Napoli: Sellino, 2007.

CARONI, Pio. Saggi sulla storia della codificazione. Milano: Giuffrè, 1998. 
CATELLANI, Enrico L. Il diritto internazionale privato e i suoi recenti progressi. Torino: Unione Tipografico-Editrice, 1902.

CAVANNA, Adriano. Storia del diritto moderno in Europa. v. 1. Milano: Giuffrè, 1982.

. Storia del diritto moderno in Europa. v. 2. Milano: Giuffrè, 2005.

COING, Helmut. Handbuch der Quellen und Literatur der neuren europäischen Privatrechtsgeschichte. Erster Band: Mittelalter (11001500). Die gerlehrten Recht und die Gesetzgebung. München: Beck Juristicher, 1973.

COLAO, Floriana. L"idea di nazione" nei giuristi italiani tra ottocento e novecento. Quaderni fiorentini per la storia del pensiero giuridico, XXX, 2001.

COSTA, Pietro. Civitas, respublica, corpus. Immagini dell'ordine e dell'appartenenza fra "antico" e "moderno". In: CARILLO, Gennaro (a cura di). Unità e disunione della polis. Napoli: Sellino, 2007.

. Civitas. Storia della cittadinanza in Europa. v. II: L'età delle Rivoluzioni. Roma: Laterza, 2000.

CURCIO, Carlo. Nazione Europa umanità: saggi sulla storia dell'idea di nazione e del principio di nazionalita in Italia. Milano: Giuffrè, 1950.

DAL RI JR., Arno. A Nação contra o Estado. A ciência do direito internacional no 'Risorgimento' italiano. Anuário Brasileiro de Direito Internacional, VI, 2011.

DAL RI Jr., Arno. Apresentação. In: SAVIGNY, Friedrich Carl von. Sistema do direito romano atual. v. VIII. Ijuí: Editora Unijuí, 2004.

. História do direito internacional: comércio e moeda.

Cidadania e nacionalidade. Florianópolis: Fundação Boiteux, 2004.

DILCHER, Gerhard. Bürgerrecht und Stadtverfassung im europäischen Mittelalter. Köln-Weimar-Wien: Böhlau, 1996.

ELLUL, Jacques. Histoire des institutions. Le moyen age. Paris: PUF, 1999. 
FERRAJOLI, Luigi. A soberania no mundo moderno. São Paulo: Martins Fontes, 2002.

FIORAVANTI, Maurizio (a cura di). Lo stato moderno in Europa. Roma-Bari: Laterza, 2002.

FLECKENSTEIN, Josef; STACKMANN, Karl (Hrsg.). Über Bürger. Stadt und städtische Literatur im Spätmittelalter. Göttingen: Vandenhoeck und Ruprecht, 1980.

GILLI, Patrick. Cidades e sociedades urbanas na Itália medieval. Séculos XII-XIV. Campinas: Unicamp, 2011.

GIORGINI, Giovanbattista. Dell'Unità d'Italia in ordine al diritto e alla storia. Considerazioni. Milano: Redaelli, 1861.

GROSSI, Paolo. L'ordine giuridico medieval. Roma: Laterza, 1995.

. Mitologias jurídicas da modernidade. 2. ed. Florianópolis: Fundação Boiteux, 2007.

. O sistema jurídico medieval e a civilização medieval. Texto da conferência introdutória ao Congresso sobre "A civilização comunal italiana na historiografia internacional" organizado em Pistoia, em 9 e 10 de abril de 2005, no "Centro Studi sulla Civilità Comunale".

Rey, 2010.

. O direito entre poder e ordenamento. Belo Horizonte: Del-

GUTZWILLER, Max. Le développement historique du droit international privé. Recueil des Cours de l'Académie de Droit International de La Haye, 29 (1929).

HEERS, Jacques. La ville au Moyen Age en occident: paysages, pouvoirs et conflits. Paris: Fayard, 1990.

JAYME, Erik. Pasquale Stanislao Mancini. Il diritto internazionale privato tra Risorgimento e attività forense. Padova: CEDAM, 1988.

KOSKENNIEMI, Martti. The gentle civilizer of nations 1870-1960. Cambridge: Cambridge University Press, 2001. 
LOPEZ DE OÑATE, Flavio. Introduzione. In: MANCINI, Pasquale Stanislao. Saggi sulla nazionalità. Bergamo: Sestante, 1944.

LUPI, João; DAL RI, JR., Arno. Humanismo Medieval: caminhos e descaminhos. Ijuí: Editora Unijuí, 2005.

MANCINI, Pasquale Stanislao. Direito Internacional. Ijuí: Unijuí, 2003.

. Rapporto a l'Institut de Droit International. In: Della nazionalità come fondamento del diritto delle genti. Torino: $\mathrm{G}$. Giappichelli Editore, 2000.

. Utilità di rendere obbligatorie per tutti gli Stati, sotto la forma di uno o piu trattati, alcune regole del diritto internazionale privato per assicurare la decisione uniforme dei conflitti tra le diferenti legislazioni civili e criminali. Il Filangieri, 1876.

MAZZINI, Giuseppe. Nazionalità. Qualche idea su una costituzione nazionale. In: Edizione nazionale degli scritti di Giuseppe Mazzini. v. VI. Imola: Galeati, 1908.

MEIJERS, Eduard Maurits. L'histoire des principes fundamenaux du droit international privé a partir du moyen age. Spécialement dans l'europe occidentale. Recueil des Cours de l'Académie de Droit International de La Haye, 49, (1934).

NICHOLAS, David. The Growth of the Medieval City. From Late Antiquity to the Early Fourteenth Century. London-New York: Longman, 1997.

NUZZO, Luigi. Da Mazzini a Mancini: il principio di nazionalitá tra politica e diritto. Giornale di storia costituzionale, 14, (2007).

POSENATO, Naiara. Bartolus de Saxoferrato e a Teoria Italiana dos estatutos. In: LUPI, João. DAL RI, JR., Arno. Humanismo medieval: caminhos e descaminhos. Ijuí: Editora Unijuí, 2005.

ROSSI, Pietro (a cura di). Modelli di città. Strutture e funzioni politiche. Torino: Einaudi, 1987. 
SAVIGNY, Friedrich Carl von. Geschichte des Röminschen Rechts im Mittelalter. Heidelberg: Mohr, 1831.

. Sistema do direito romano atual. v. VIII. Ijuí: Editora Unijuí, 2004.

. System des heutigen römischen Rechts. Erster Band. Berlin: Veit und Comp., 1849.

SCAJOLA, Vittorio. Diritto e giuristi nel Risorgimento italiano. In: SCAJOLA, Vittorio. Studi giuridici. v. V. Diritto publico. Roma: Anonima Romana, 1936.

SEGOLONI, Danilo (Ed.). Bartolo da Sassoferato: Studi e documenti per il IV centenario. Milano: Giuffrè, 1962.

STRENGER, Irineu. Direito processual internacional. São Paulo: LTr, 2003.

TARELLO, Giovanni. Ideologias setecentistas da codificação e estrutura dos códigos. Meritum, FUMEC, Belo Horizonte, 2008.

TANZI, Aristide. L'antiformalismo giuridico. Percorso antologico. Milano: Raffaello Cortina, 1999.

TREVES, Renato. La cultura giuridica tedesca tra neokantismo e neohegelismo. In: TANZI, Aristide. L'antiformalismo giuridico. Percorso antologico. Milano: Raffaello Cortina, 1999.

VALADÃO, Haroldo. Direito internacional privado. v. III: Parte Especial. Rio de Janeiro: Freitas Bastos, 1978.

VALLERANI, Massimo. La città e le sue istituzioni. Ceti dirigenti, oligarchia e politica nella medievistica italiana del Novecento. In: Annali dell'Istituto storico italo-germanico in Trento, XX, (1994).

VIORA, Mario. Consolidazioni e codificazioni: contributo alla storia della codificazione. Torino: S. P. E., 1967.

WALEY, Daniel P. Le città-repubblica dell'Italia medievale. Torino: Einaudi, 1980.

WOOLF, C. Bartolo of Sassoferato. His Position in the History of Medieval Political Thought. Cambridge: Cambridge University Press, 1913. 